\title{
Psychometric properties of the Spanish validation of the Five Facets of Mindfulness Questionnaire (FFMQ)
}

\author{
A. Cebolla*,** \\ A. García-Palacios ${ }^{\star, \star *}$ \\ J. Soler ${ }^{\star \star \star}$ \\ V. Guillen ${ }^{\star \star \star \star}$ \\ R. Baños ${ }^{\star \star, \star \star \star \star \star}$ \\ C. Botella ${ }^{*, \star *}$
}

* Universitat Jaume I. Castelló

** CIBER Fisiopatología Obesidad y Nutrición (CB06/03), Instituto Carlos III

${ }^{* * *}$ Hospital de San Pau i la Santa Creu

**** PREVI Clinical Center

$\star \star \star \star \star$ Universitat de València

SPAIN

\begin{abstract}
Background and Objectives: Mindfulness-based therapies have demonstrated effectiveness in many clinical contexts. Various therapies that train mindfulness skills have proliferated in recent years. There is increasing interest in mindfulness-based therapies and in incorporating instruments that measure mindfulness in order to understand its role in clinical and basic research. The Five Facets of Mindfulness Questionnaire (FFMQ) is a questionnaire for measuring mindfulness; it was derived from a factor analysis of five different questionnaires that measure a trait-like general tendency to be mindful in daily life. The objective of this study is to validate the FFMQ in a Spanish sample.

Methods: The FFMQ was administered to a sample of 462 subjects ranging from 18 to 63 years $(X=27.9 ; \mathrm{SD}=9.75)$. The sample was composed by clinical $(\mathrm{n}=146)$ and nonclinical $(\mathrm{n}=226)$ subsamples.

Results: The internal reliability of the scales ranged from acceptable to very good. Convergent analysis was conducted by computing Pearson's correlations, showing high correlations. The factorial structure is the same as that proposed by Baer et al.

Conclusions: The FFMQ proved to be an effective instrument for measuring mindfulness in clinical and non-clinical Spanish samples.
\end{abstract}

Received: 5 May 2011

Revised: 31 January 2012

Accepted: 6 February 2012 


\section{Introduction}

Mindfulness is defined as "focusing attention in an intentional way: on an object, on the present moment, and without judging"1. Humans are normally scarcely aware of their experiences from moment to moment, and therefore usually act on "automatic pilot"2 In recent years there has been an increase in the number of studies on the efficacy of therapies that apply mindfulness techniques to a wide variety of disorders and symptoms ${ }^{2-5}$. There are important differences between therapies that employ mindfulness, but they share the role of accepting experiences, whether pleasant or unpleasant, as one of the routes to improving both mental and physical health ${ }^{6}$, in addition, they all depend on the stimulation and learning of mindfulness skills to achieve their aims.

There is great interest in mindfulnessbased therapies in incorporating instruments that measure mindfulness ${ }^{7}$ in order to conduct clinical and basic research and to understand the mechanisms that underlie the process of change. Mindfulness and acceptance therapies assume that mindfulness is an intrinsic state that all humans can cultivate though a variety of techniques. Hence, there will be within-subject differences (subjects mindfulness skills might change depending on the time or the context), and between-subject differences (subjects will have varying levels of these skills).

The Five Facets of Mindfulness Questionnaire $(\mathrm{FFMQ})^{8}$ is a questionnaire for measuring mindfulness, and was derived from a factor analysis of previous questionnaires measuring a trait-like general tendency to be mindful in daily life. The scales that were used in the factorization of the FFMQ were the Kentucky Inventory Mindfulness Skills (KIMS) ${ }^{9}$, Freiburg Mindfulness In- ventory $(\mathrm{FMI})^{10}$, Mindfulness Questionnaire $(\mathrm{MQ})^{11}$, Mindfulness Attention Awareness Scale (MAAS) ${ }^{12}$ and the Cognitive and Affective Mindfulness Scale (CAMS) ${ }^{13}$. The FFMQ has shown to have good internal consistency and significant relationships in the predicted directions with a variety of constructs related to mindfulness ${ }^{8}$. The FFMQ correlates positively with openness to experience, emotional intelligence, and negatively with psychological distress ${ }^{8}$. Previous research has indicated that the FFMQ is sensitive to differences between practicing mindfulness and non-practicing ${ }^{14,15}$, and are directly related to improvements in symptomatology after a mindfulness-based therapy $^{16}$. It has been validated into Dutch ${ }^{17}$ and Chinese $^{18}$ showing excellent psychometric properties in both validations.

The objective of this study is to validate the FFMQ in a Spanish sample. The reasons for selecting the FFMQ to be validated include that it is sensitive to intervention ${ }^{16,19,20}$, and that it has five factors, thus it identifies which skills are the most important predictors of symptom reduction and increased well-being, and the mechanisms through which these beneficial effects occur ${ }^{21}$.

\section{Methods}

\section{Participants}

The sample was composed by 462 participants (232 men and 231 women), with a mean age of $27.4(\mathrm{SD}=8.3)$, ranging from 16 to 63 years. The sample was composed of clinical $(n=146)$ and non-clinical samples $(\mathrm{n}=316)$. The non-clinical sample included 316 participants (198 men and 104 women), who were recruited among undergraduates and postgraduates enrolled in Psy- 
chology studies at the University of Valencia and Castellón (Spain), and the general community. The mean age for the non-clinical sample was $26.1(\mathrm{SD}=8.4)$. The clinical sample included 146 participants (25 men and 120 women) who were recruited from two mental health units, PREVI ( $\mathrm{n}=46$, Valencia, Spain) and the Hospital de la Santa Creu i Sant Pau ( $n=100$; Barcelona, Spain). The clinical sample was diagnosed with several mental disorders including borderline personality disorder $(n=44)$, cluster $C$ personality disorder $(n=16)$, major depression $(n=10)$, eating disorder $(n=37)$ and cocaine addiction $(\mathrm{n}=24)$. The mean age was $30.5(\mathrm{SD}=8.3)$.

\section{Procedure}

The clinical group completed all measures during an outpatient clinic visit at the hospital. The diagnosis was conducted by staff from the clinical centers (clinical psychologists and psychiatrists), according to DSM-IV-TR ${ }^{22}$. The non-clinical sample filled out the questionnaires in a classroom. They were informed about the purpose of the study and that their answers were to be treated confidentially. Before filling out the questionnaires, all participants were asked to sign an informed consent. Participation was completely voluntary, with no economic or academic incentives. The FFMQ (forward translation) was translated by mindfulness experts and then revised by a bilingual psychologist from the USA (backward translation). The discrepancies between both translations were resolved by a professional English translator ${ }^{23}$.

\section{Instruments}

Five Facets of Mindfulness Questionnaire ${ }^{8}$ : This questionnaire consists of 39 items that assess five facets of mindfulness. Items are rated on a Lickert scale ranging from 1 (never or very rarely true) to 5 (very often or always true). The factors include: Observing, including noticing or attending to internal and external experiences such as sensations, thoughts, or emotions. Describing refers to labeling internal experiences with words. Acting with awareness includes focusing on one's activities in the moment as opposed to behaving mechanically. Nonjudging of inner experience refers to taking a non-evaluative stance toward thoughts and feelings. Finally, non-reactivity to inner experience is allowing thoughts and feelings to come and go, without getting caught up in or carried away by them ${ }^{14}$.

Acceptance and Action Questionnaire ${ }^{24}$. This scale includes nine items organized in one category, and was developed for measuring acceptance and avoidance. Items are rated on a Lickert scale ranging from 1 (never true) to 7 (always true). A version validated in the Spanish population was used ${ }^{25}$.

Brief Symptom Questionnaire-49 items ${ }^{26}$. This is a scale of 49 items developed by Derogatis $^{27}$ to assess symptoms of psychological disorders. It includes six factors: depression, phobic anxiety, paranoia, obsession, somatization and hostility. Each item is rated on a five-point scale ( 0 to 4 ) according to manifestations of symptoms in the last 30 days (ranging from "not at all" to "extremely"). A Global Severity Index (GSI) is also calculated, as a measure of global discomfort. The Spanish version of this scale was used in this study ${ }^{28}$.

Mindfulness and Awareness Scale (MAAS) ${ }^{12}$. This 15-item scale measures the frequency of mindfulness states in daily life. Based on a mean of all items, MAAS scores can range from 1 (almost always) to 6 (almost never). This questionnaire is not validated into Spanish language. It was translated according to standard recommendations ${ }^{23}$. 


\section{Results}

All five scales demonstrated good internal consistency (Table 1). Computation of internal consistency for the present data showed an alpha coefficient of 0.88 for the
FFMQ total score. The scale's alpha values of each factor of the Spanish and English version are shown in table 1 . In the correlational analysis among FFMQ scales, results indicated a significant correlation among all of the scales (Table 2).

Table 1

Descriptives and Cronbach's $\alpha$ for each factor of the Spanish and English versions of the FFMQ

\begin{tabular}{llccc} 
& M & SD & $\begin{array}{c}\text { Cronbach } \alpha \text { for } \\
\text { Spanish version }\end{array}$ & $\begin{array}{c}\text { Cronbach } \alpha \text { for } \\
\text { English version }\end{array}$ \\
\hline Observing & 23.6 & 5.6 & 0.81 & 0.83 \\
Describing & 28.7 & 6.5 & 0.91 & 0.91 \\
Acting Aware & 27 & 6.6 & 0.89 & 0.87 \\
Non-judging & 26.8 & 7.4 & 0.91 & 0.87 \\
Non-reacting & 20.6 & 4.5 & 0.80 & 0.75 \\
\hline
\end{tabular}

Table 2

Correlations between mindfulness factors and related constructs

\begin{tabular}{|c|c|c|c|c|c|}
\hline & Observing & Describing & Acting Aware & Non-judging & Non-reacting \\
\hline AAQ & 0.02 & $0.35 * *$ & $0.45 * *$ & $0.64 * *$ & $0.59 * *$ \\
\hline \multicolumn{6}{|l|}{ BSI-48 } \\
\hline Depression & 0.04 & $-0.36 * *$ & $-0.44 * *$ & $-0.60 * *$ & $-0.48 * *$ \\
\hline Anxiety & 0.15 & $-0.20^{*}$ & $-0.29 * *$ & $-0.50 * *$ & $-0.37 * *$ \\
\hline Paranoia & 0.07 & $-0.42 * *$ & $-0.44 * *$ & $-0.59^{* *}$ & $-0.41^{* *}$ \\
\hline Obsession & 0.10 & $-0.37 * *$ & $-0.50 * *$ & $-0.63^{* *}$ & $-0.40^{* *}$ \\
\hline Somatization & 0.14 & $-0.24 * *$ & $-0.41 * *$ & $-0.51 * *$ & $-0.32 * *$ \\
\hline Hostility & 0.10 & $-0.20^{*}$ & $-0.32 * *$ & $-0.49 * *$ & $-0.25^{* *}$ \\
\hline IGS & 0.10 & $-0.037 * *$ & $-0.50 * *$ & $-0.64 * *$ & $-0.43^{* *}$ \\
\hline MAAS & -0.03 & $0.27 * *$ & $0.64 * *$ & $0.41^{* *}$ & $0.25^{* *}$ \\
\hline Observe & & $0.18 * *$ & $-0.13^{*}$ & $-0.20^{* *}$ & $0.19 * *$ \\
\hline Describe & & & $0.38 * *$ & $0.26^{* *}$ & $0.31 * *$ \\
\hline Act with Awareness & & & & $0.44 * *$ & $0.21 * *$ \\
\hline Accept without judgement & & & & & $0.33 * *$ \\
\hline
\end{tabular}

AAQ: Acceptance and Action Questionnaire; BSI-48: Brief Symptom Inventory-48; IGS: Global Severity Index; MAAS: Mindfulness and Awareness Scale;

$*<0.05 ; * *<0.001$. 
The convergent and divergent validity of the FFMQ (Table 2) were calculated using Pearson's product-moment correlations with other relevant measures of psychopathology, other mindfulness and acceptance measures. All of the FFMQ scales correlated negatively with all of the psychopathological factors, except observing. The mindfulness scale that shows higher correlations with psychopathology measures is the non-judging of inner experience factor.

Among the mindfulness scales, the correlational analyses showed significant positive relationships, unless the correlation of the observing scale with acting with awareness scale ( $\mathrm{p}=0.003)$ and the non-judging of inner experience scale $(\mathrm{p}<0.001)$. The strongest positive relations are between acting with awareness and non-judging of inner experience $(\mathrm{p}<0.001)$ factors.

\section{Confirmatory factor analysis}

Several Confirmatory Factor Analyses (CFAs) were applied to explore the goodness of fit indices for the factorial model of the FFMQ. Maximum likelihood CFAs were conducted using the EQS 6.1 program $^{29}$. Prior to the CFA, an item parcels (groups of items) was used rather than individual items, as were used in the original validation made by $\mathrm{Baer}^{8}$. For each factor, items were assigned sequentially to item groups in the order in which they appear on the instrument (first item to Group 1, next item to Group 2, etc.). An average of these items was used. This yielded a total of 15 groups (3 items per factor), each being the average of two or three items (Table 3 ).

Parceling is a measurement practice that is used in multivariate approaches to psy-

Table 3

Factor saturations for each parcel from FFMQ

\begin{tabular}{lccccc} 
& Observing & Describing & Acting Aware & Non-judging & Non-reacting \\
\hline Parcel 1 & 0.973 & & & \\
Parcel 2 & 0.587 & & & \\
Parcel 3 & 0.769 & & & \\
Parcel 4 & & 0.910 & & \\
Parcel 5 & 0.904 & & & \\
Parcel 6 & 0.870 & & & \\
Parcel 7 & & 0.944 & & \\
Parcel 8 & & 0.824 & 0.828 & \\
Parcel 9 & & 0.851 & 0.917 & \\
Parcel 10 & & & 0.855 & \\
Parcel 11 & & & & 0.784 \\
Parcel 12 & & & & 0.749 \\
Parcel 13 & & & & \\
Parcel 14 & & & & \\
Parcel 15 & & & & \\
\hline
\end{tabular}


chometrics, particularly for use with latentvariable analysis techniques. It is used for a variety of data problems, like small sample sizes, non-normality, or unstable parameter estimates $^{30}$. Several benefits of this methodology have been previously described. Firstly, the reliability of a group of items is greater than that of single items; hence, groups can serve as more stable indicators of a latent construct. Furthermore, groups provide more scale points, thereby more closely approximating continuous measurement of latent constructs and provide more efficient estimates of latent parameters than items $\mathrm{do}^{31,32}$.

Assessment of model fit was performed using the goodness-of-fit $\chi^{2}$ test statistic. Another index used to assess the adequacy of each model was the comparative fit index (CFI), which compares the fit of the model to a null model and establishes the absence of relationships among the variables. The GFI and AGFI fit indices were also used, to measure the proportion of variance-covariance accounted for by the proposed model. The standardized root mean square residual (SRMS) and the root mean squared error of approximation (RMSEA) penalize the models that are not parsimonious, and they are sensitive to mis-specified factor covariance.
The following criteria were used to indicate the fit of the CFA models to the data: CFI and GFI $>0.90$ and RMSEA $<0.08$. Values for CFI and GFI ranged from 0 to $1^{32}$. These fit statistics and the chi-square were selected because previous research has demonstrated their performance and stability ${ }^{33,34}$.

Three models were considered in analyzing the structure of the FFMQ. The first model tested was the monofactorial structure, including all of the items ${ }^{8}$. The second model was a hierarchical one in which the five factors are indicators of an overarching mindfulness factor, with all of the factors intercorrelated. Finally, was tested the original model proposed by Baer ${ }^{8}$, which is a model where the factors describing, non-judging of inner experience, acting with awareness and non reactivity to inner experience are correlated with a second order factor, whereas the factor observing remained isolated. The third model showed the best fit indices (Table 4). According to the fit indices, the fivefactor model solution with the observe scale isolated was the model that best represented the observed data. The five-factor model was the one with the smallest $\chi^{2}$, while CFI and GFI indexes had the highest.

Table 4

Fit indices for confirmatory factor analytic models of the FFMQ

\begin{tabular}{|c|c|c|c|c|c|c|}
\hline & CFI & GFI & SRMR & RMSEA & ${ }_{\mathrm{sb}} \mathrm{X}^{2}$ & $\mathrm{p}$ \\
\hline First model (1 factor) & 0.387 & 0.511 & 0.182 & $\begin{array}{c}0.254 \\
{[0.245-0.262]}\end{array}$ & 1995.6043 & $\mathrm{p}<0.001$ \\
\hline $\begin{array}{l}\text { Second model } \\
\text { ( } 5 \text { factors intercorrelated) }\end{array}$ & 0.942 & 0.900 & 0.106 & $\begin{array}{c}0.060 \\
{[0.050-0.071]}\end{array}$ & 263.3217 & $\mathrm{p}<0.001$ \\
\hline $\begin{array}{l}\text { Third model } \\
\text { (4 factors intercorrelated } \\
\text { with Observing isolated) }\end{array}$ & 0.960 & 0.926 & 0.069 & $\begin{array}{c}0.071 \\
{[0.061-0.080]}\end{array}$ & 204.6924 & $\mathrm{p}<0.001$ \\
\hline
\end{tabular}

CFI = Comparative fit index; GFI = goodness of fit index; RMSEA = root mean square error of approximation (the $90 \%$ confidence interval is shown in parentheses); ${ }_{\mathrm{sb}} \mathrm{X}^{2}=$ Satorra-Bentler Chi Square. 


\section{Discussion}

The aim of this study was to analyze the psychometric properties of the FFMQ in a Spanish sample. The CFA results supported the factorial structure reported by Baer et al. ${ }^{8}$, with five factors. Thus, the Spanish translation of the FFMQ appears to measure the same five constructs as the original version.

According to factorial structure, the CFA data suggested that, as Baer et al. ${ }^{8}$ demonstrated, the factors describing, acting with awareness, non-judging of inner experience, and non-reactivity to inner experience are elements of an overarching mindfulness construct, and the fit indices are better when the observing scale is isolated. As Baer indicated, although observing is a component of the mindfulness definition, it is only significant, and only correlates with the other factors, for experienced mindfulness practicing $^{8}$. Furthermore, the sample recruited for this study included a significant percentage of people with various mental disorders. This is significant, since our results show differences from Baer's results ${ }^{8}$.

The FFMQ scales reflected adequate internal consistency, similar to those reported by Baer et al. ${ }^{8}$ (alphas from 0.75 to 0.91 ). In the correlations with other scales, the FFMQ showed an expected and significant relationship with almost every scale, except $o b$ serving. The observing factor includes attention to both internal stimuli and external stimuli $^{14}$. As previously mentioned, observing correlates significantly with psychological adjustment in experienced mindfulness practice who notice a wide range of stimuli, which is therapeutic when accompanied by a non-judgmental style. However, in clinical samples, observing might be related to focusing on threats or unpleasant experiences. As Watkins and Teasdale ${ }^{35}$ noted, there are different kinds of self-focus, each with different functional properties. Ruminative, analytical self-focus is maladaptive and related to psychopathology, while experiential, nonanalytical self-focus (mindfulness) is adaptive. The suitability of keeping observing in the FFMQ when it is used to measure clinical samples or non-clinical populations should be considered, since it is only sensitive to and measures the correct constructs in samples of experienced mindfulness practicing.

Contrary to the original validation ${ }^{8}$, in the present study the observing scale presented a slightly negative relationship with the other mindfulness scales. Observing and $a c$ ting with awareness had a positive relationship in the original validation, while in the present study this relation is slightly negative. This different relation might be explained by sample characteristics, given that in the present study almost $40 \%$ of the participants were recruited from a clinical context and were diagnosed with serious mental disorders. The remaining scales are positively correlated as predicted, given that they are considered different factors of the same construct.

Our study has several notable limitations. Firstly, our sample size is moderate, and inter-rater and test-retest reliability were not tested. Future studies should be conducted to investigate various mindfulness patterns in different clinical samples, and also the potential differences in factorial structure and scoring in the FFMQ between clinical and non-clinical groups.

The main contribution of this work is to provide a validation of a mindfulness measure for the Spanish population. Our data support the possibility of using the FFMQ in Spanish clinical and nonclinical samples. We have available an instrument that measures mindfulness that is sensitive to intervention 
and that includes five different skills. We believe this questionnaire will be useful in future research to measure the effect of mindfulness interventions in Spanish samples.

In conclusion, the primary objective of this study was to explore the psychometric properties of the Spanish translation of the FFMQ. This objective was accomplished; the FFMQ has proven to be an effective instrument for measuring mindfulness in Spanish samples.

\section{Acknowledgements}

CIBERobn is an initiative of ISCIII. This research has been made possible, in part, by the support of Ministerio de Ciencia e Innovación (Plan Nacional de Investigación Científica, Desarrollo e Innovación Tecnológica 2008-2011), in the project (PSI200804392/PSIC), and the Excelence Research Program PROMETEO (Generalitat Valenciana. Conselleria de Educación; 2008/157).

We thank Dr. Ruth Baer for granting us permission to adapt the Five Facets of Mindfulness Questionnaire.

\section{References}

1. Kabat-Zinn J. Full catastrophe living: Using the wisdom of your body and mind to face stress, pain and illness. New York: Delacorte; 1990.

2. Segal ZV, Williams JMG, Teasdale JD. Mindfulnessbased cognitive therapy for depression: A new approach to preventing relapse. New York: Guilford; 2002.

3. Baer RA. Mindfulness training as a clinical intervention: A conceptual and empirical review. Clin Psychol Sci Pract 2003; 10: 125-143.

4. Hayes SC, Strosahl K, Wilson KG. Acceptance and commitment therapy: An experiential approach to behavior change. New York: Guilford; 1999.
5. Witkiewitz K, Marlatt GA, Walker D. MindfulnessBased Relapse Prevention for Alcohol and Substance Use Disorders: The meditative tortoise wins the race. J Cognitive Psychother 2006; 19: 221-228.

6. Bishop SR, Lau M, Shapiro S, Carlson L. Mindfulness: a proposed operational definition. Clin Psychol Sci Pract 2004; 11: 230-241.

7. Grossman P. On measuring Mindfulness in psychosomatic and psychological research. J Psychosom Research 2008; 64: 405-408.

8. Baer R, Smith GT, Hopkins J, Krietemeyer J, Toney L. Using Self-Report Assessment to Explore Facets of Mindfulness. Assessment 2006; 13: 27- 45.

9. Baer R, Smith GT, Allen KB. Assessment of Mindfulness by self-report: The Kentucky Inventory of Mindfulness Skills. Assessment 2004; 11: 191-206.

10. Buchheld N, Grossman P, Walach H. Measuring Mindfulness in Insight Meditation and Meditation-Based Psychotherapy: The development of the Freiburg Mindfulness Questionnaire (FMI). Journal for Meditation and Meditation Research 2001; 1: 11-34.

11. Chadwick P, Hember M, Symes J, Peters E, Kuipers E, Dagnan D. Responding mindfully to unpleasant thoughts and images: reliability and validity of the Southampton mindfulness questionnaire (SMQ). Br J Clin Psychol 2008; 47: 451-455.

12. Brown KW, Ryan RR. The benefits of being present: Mindfulness and its role in Psychological Well-being. J Pers Soc Psychol 2003; 84: 822-848.

13. Feldman GC, Hayes AM, Kumar SM, Greeson JM. Development, factor structure, and initial validation of the Cognitive and Affective Mindfulness Scale. 2004. Unpublished manuscript.

14. Baer R, Smith GT, Lykins E, Button D, Krietemeyer J, Sauer S., et al. Construct validity of the five facet mindfulness questionnaire in meditating and nonmeditating samples. Assessment 2008; 15: 329-342.

15. Van Dam NT, Earlywine M, Danoff-Burg S. Differential item function across meditators and non-meditators on the Five Facet Mindfulness Questionnaire. Pers Ind Diff 2009; 47: 516-521.

16. Kuyken W, Watkins E, Holden E, White K, Taylor RS, Byford S, et al. How does mindfulness-based cognitive therapy work? Behav Res Ther 2010; 48: 1105-1112.

17. Isenberg L. Mindfulness: Life with attention and awareness. Test-retest reliability of the FFMQ for Dutch fibromyalgia patients. Pers Ind Diff. 2010. http://essay. utwente.n1/59356 [Accesed the 08-Augut-2010]. 
18. Deng YQ, Liu XH, Rodriguez MA, Xia CY. The five facet mindfulness questionnaire: Psychometric Properties of the Chinese Version. Mindfulness 2011; 2: 123-128.

19. Cebolla A, Miró MT. Eficacia de la Terapia Cognitiva basada en la Atención Plena en el tratamiento de la depresión. Revista de Psicoterapia 2007; 66/67: 133-157.

20. Carmody J, Baer R. Relationships between Mindfulness Practice and Levels of Mindfulness, Medical and Psychological Symptoms and Well-being in a MindfulnessBased Stress Reduction Program. J Behav Medicine 2008; 31: 23-33.

21. Cash M, Whittingham K. What facets of Mindfulness contribute to psychological well-being and depressive, anxious, and stress-related symptomatology? Mindfulness 2010; 1: 177-182.

22. American Psychiatric Association. Diagnostic and Statistical Manual of Mental Disorders, Text Revision, $4^{\text {th }}$ ed. Washington, DC: American Psychiatric Association; 2000.

23. Muñiz J, Hambleton RK. Directrices para la traducción y adaptación de los test. Papeles de Psicólogo; 1996. http://www.papelesdelpsicologo.es/vernumero.asp?id=737 [Accesed the 30/04/2005].

24. Hayes SC, Strosahl K, Wilson, KG, Bissett, RT, Batten SV, Bergan J, et al. The Acceptance and Action Questionnaire (AAQ) as a measure of experiential avoidance. Psychological Record 2006; 54: 553-578.

25. Barraca J. Spanish adaptation of the Acceptance and Action Questionnaire (AAQ). Int J Psychol Psychol Ther 2004; 4: 505-515.

26. Derogatis LR, Melisaratos N. The Brief Symptom Questionnaire: An introductory report. Psychol Medicine 1983; 13: 595-605.
27. Derogatis LR. Brief Symptom Questionnaire. Baltimore: Clinical Psychometric Research; 1975.

28. Ruiperez MA, Ibañez MI, Lorente E, Moro M, Ortet G. Psychometric Properties of the Spanish version of the BSI. Eur J Psychol Assess 2001; 17: 241-250.

29. Bentler PM. EQS structural equations program manual. Encino, CA: Multivariate Software; 1995.

30. Bandalos DL. The effect of item parceling on goodness-of-fit and parameter estímate bias in structural equation modeling. Struct Equ Modeling 2002; 9: 78-102.

31. Little TD, Cunningham WA, Shahar G, Widamon KF. To parcel or not to parcel: Exploring the question, weighing the merits. Struct Equ Modeling 2002; 9: 151-173.

32. Rushton JP, Brainerd CJ, Pressley M. Behavioral development and construct validity: The principle of aggregation. Psychol Bull 1983; 94: 18-38.

33. Hu LT, Bentler PM. Cut-off criteria for fit indexes in covariance structure analysis: conventional criteria versus new alternatives. Struct Equ Modeling 1990; 6: 1-55.

34.Bentler PM, Bonett DG. Significance tests and goodness of fit in the analysis of covariance structures. Psychol Bull 1980; 47: 541-570.

35. Watkins E, Teasdale JD. Adaptative and maladaptative self-focus in depression. J Affect Disord 2004; 82: 1-8.

Author for correspondence:

Ausiàs Cebolla i Martí PhD

University Jaume I, Castelló de la Plana

Avda. Sos Banyat s/n

Phone: 964387643

E-mail: acebolla@psb.uji.es 